\title{
Deterministic?: Newspaper Representations of Obesity and Genetics
}

\author{
T. Caulfield*, V. Alfonso and J. Shelley \\ Health Law Institute, University of Alberta, Canada
}

\begin{abstract}
Media coverage of the role of genetics in obesity causation may influence health behaviours as well as public support for obesity prevention policies. This study examined the five highest circulating daily newspapers for articles addressing genetics and obesity between January 1, 1990 and June 14, 2007. Of 776 articles found, 109 were reviewed. Results indicate a shift away from a deterministic view of obesity towards a personal responsibility perspective over time. These findings may have implications for public policy.
\end{abstract}

\section{INTRODUCTION}

There has long been speculation and concern that media coverage simplifies and distorts the role of genetics in the development and expression of human traits, thus heightening an inappropriately deterministic view of genes [1]. While the available evidence regarding determinism is far from conclusive [2], this concern remains a common theme in academic literature and there is at least some evidence that deterministic portrayals could have an adverse impact on behaviour and attitudes [3], including attitudes and behaviours pertaining to obesity [4]. Moreover, media coverage of obesity contributes to the public's understanding of obesity aetiology. Causal explanations of obesity are strongly associated with both support of obesity prevention programs and policies and government protections for overweight and obese people. Specifically, those who attribute obesity to genetic or environmental factors are more likely to support obesity prevention policies as well as governmental protections, whereas those who attribute obesity to poor lifestyle choices are less likely to support such policies and protections $[5,6]$.

Obesity has emerged as a serious public health dilemma, with genetics recognized as having a causal role (though the nature of the role of genetics remains an open question) [7]. With the discovery of obesity related genes and proteins, the contributory role of genetics in obesity is often discussed in the media. This coverage provides an opportunity to do a systematic analysis of how the popular press represents the role of genetics in a complex, multi-factorial condition. Specifically, this study examines the degree to which the media presents obesity as genetically determined.

\section{METHODS}

Using the search engines Factiva and Lexis-Nexis and search terms that captured stories referring to both obesity and genetics, we collected newspaper articles from the five highest circulating US dailies: the L.A. Times, the New York

*Address correspondence to this author at the Faculty of Law and School of Public Health, Health Law Institute, Law Centre, University of Alberta, Canada; Tel: 780-492-8358; Fax: 780-492-9575;

E-mail: tcaulfld@law.ualberta.ca
Times, the Wall Street Journal, the Washington Post, and U.S.A. Today. Publication dates ranged from January 1, 1990 to June 14, 2007. This search yielded 776 results. A random number generator was used to select $25 \%$ for inclusion in the study $(n=195)$, of which 109 met our coding criteria (a unique story about genetics and obesity). The breakdown by year is as follows: 2005-2007: 21; 2002-2004: 29; 19992001: 19; 1996-1998: 19; 1993-1995: 14; and 1990-1992: 7.

A coding frame was developed based on a strategy utilized in other contexts [8]. The coding frame included specific questions, such as: "which potential sources of obesity does the article discuss?" The questions were followed by a list of possible answers. All articles were scored by a single coder and, in order to assess inter-coder reliability, a randomly selected $10 \%$ were scored by another coder (Kappa scores ranged from 0.616 - 1.0 - indicating good to excellent inter-coder reliability).

\section{RESULTS}

Given our search terms, it is no surprise that genetics was the most often mentioned contributory cause of obesity in the articles $(86 \%$ - 94/109). But other factors, such as lifestyle $(83 \%$ - 90/109) and environment (44\% - 48/109), were also frequently canvassed. Government $(7 \%-8 / 109)$ and industry $(3 \%-3 / 109)$ received less attention.

The articles also mentioned a wide range of possible solutions to the obesity issue, including lifestyle (73\%), pharmacologic interventions (33\%), use of genetic therapies (18\%), medical (non-pharmacologic or genetic interventions, $17 \%$ ), environmental (17\%), and government (regulation/ law-making $8 \%$ ). We found that the reference to lifestyle increased from 1999 onward. After that date, it appears at least $74 \%$ of the time in each year. This is a departure from the relatively low weight given to lifestyle factors between, for example, 1996 and 1998, where it is mentioned only $47 \%$ of the time.

In addition, we found a corresponding trend with respect to a de-emphasis on portraying genetics as the central determinant of obesity (see Fig. 1). Between 1996 and 1998, genetics was portrayed as a central determinant of obesity $58 \%$ of the time, with another $11 \%$ of articles discussing only genetic factors for obesity. Between 1999 and 2001, 


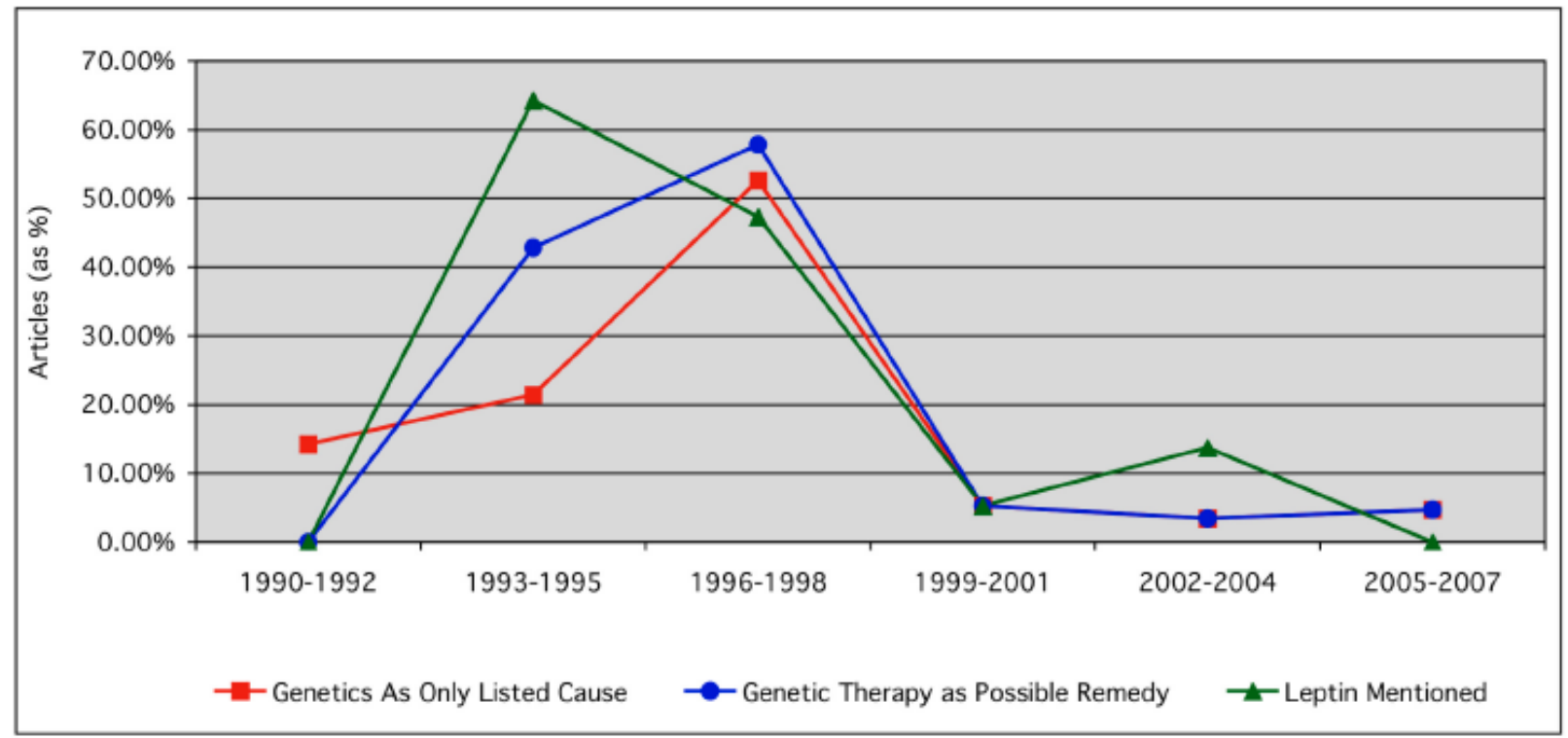

Fig. (1). Genetics as only listed cause, genetic therapy as possible remedy, and mentioning of leptin: 1990-2007.

only $5 \%$ of articles fell within the former category, whereas none were scored in the latter between 1999 and 2007. The discussion of a possible genetic based therapy or pharmacological intervention, such as flowing from research on the neurotransmitter leptin, followed a surprisingly similar pattern (see Fig. 1).

\section{DISCUSSION}

This analysis found a noticeable shift away from a deterministic framing of obesity. After 1999, stories about obesity genes increasingly portrayed obesity as a disease for which individuals are personally responsible (lifestyle was coded as a proxy for notions of individual responsibility), with lifestyle identified both as a cause and a remedy, rather than being caused by unchangeable environmental or genetic factors. It appears that when the gene stories first appear, the deterministic possibilities dominate the frame. As the obesity gene story evolves with time, the media's tendency to place to locus of responsibility on the individual returns. Indeed, other studies of media portrayals of obesity have found an "unbalanced emphasis on personal responsibility in public health" [9].

There are clear limitations to our study. For example, it only looked at print media and not other news sources, such as TV and blogs. Likewise, our analysis does not tell us exactly why the media's frame shifts, an issue that warrants further investigation. But these findings are consistent with public perceptions of obesity causation, namely, the majority of the public have attributed obesity to lifestyle factors. In 2001 , only $40 \%$ of a representative, American sample thought obesity was heritable and $18 \%$ thought obese people were simply "born that way." Contrastingly, $65 \%$ of the same sample attributed obesity to individuals' lack of willpower to diet or exercise [5]. Beliefs and portrayals about the etiology of obesity are a strong predictor of public support for obesity policies and government protections for the obese, with those who attribute obesity to factors other than lifestyle or willpower more likely to support both policies and protections. As noted by one scholar, "[d]efining a problem in individualized terms limits governmental responsibility for addressing it, while systematic frames invite governmental action" [10]. Understanding how the media presents the obesity "problem" seems essential to the development of sustainable obesity prevention policies.

\section{CONFLICT OF INTEREST}

The authors have no conflicts to declare. The authors have no financial conflicts of interest to declare. All authors had full access to the study data and take responsibility for the integrity of the data and the accuracy of the data analysis. All authors contributed to the writing of the manuscript and the analysis of data.

\section{ACKNOWLEDGEMENTS}

We would like to thank Edna Einsiedel, PhD, Faculty of Communication and Culture, University of Calgary; Tania Bubela, LLB, PhD, Research Fellow, School of Public Health, University of Alberta, Health Law Institute, University of Alberta; Robyn Hyde-Lay, MA, MBA, Project Manager, Health Law Institute, University of Alberta; Megan Koper, BSC, Research Assistant, Health Law Institute, University of Alberta; Nola Ries, MPA, LLM, Research Associate, Health Law Institute, University of Alberta; Barbara von Tigerstrom, LLB, PhD, Faculty of Law, University of Saskatchewan; and Leia Minaker, MSc, Centre for Health Promotion, University of Alberta. We would like to thank Genome Alberta and the Canadian Institutes of Health Research for funding support.

\section{REFERENCES}

[1] Nelkin D. Molecular metaphors: the gene in popular discourse. Nat Rev Genet 2001; 2(7): 555-59.

[2] Condit CM, Ofulue N, Eds. Determinism and mass-media portrayals of genetics. Am J Hum Genet 1998; 62(2): 979-84. 
[3] Lynch J, Bevan J, Eds. A preliminary study of how multiple exposures to messages about genetics impact on lay attitudes towards racial and genetic discrimination. New Genet Soc 2008; 27(1): 43-56.

[4] Jeong S-H. Effects of news about genetics and obesity on controllability attribution and helping behavior. Health Commun 2007; 22(3): 221-28.

[5] Oliver JE, Lee T. Public opinion and the politics of obesity in America. J Health Polit Policy Law 2005; 30(5): 923-54.

[6] Hilbert A, Rief W, Eds. What determines public support of obesity prevention? J Epidemiol Commun Health 2007; 61: 585-90.
[7] Lee YS. The role of genes in the current obesity epidemic. Ann Acad Med Singapore 2009; 38(1): 45-3.

[8] Bubela T, Caulfield T. Do the print media 'hype' genetic research?: a comparison of newspaper stories and peer-reviewed research papers. Can Med Assoc J 2004; 170(9):1399-407.

[9] Kim S-H, Willis LA. Talking about obesity: news framing of who is responsible for causing and fixing the problem. $\mathbf{J}$ Health Commun 2007; 12(4): 359-76.

[10] Lawrence, R. Framing. Obesity: The evolution of news discourse on a public health issue. Press/Politics 2004; 9(3): 56-75.

Received: April 22, 2009

(C) Caulfield et al.; Licensee Bentham Open.

This is an open access article licensed under the terms of the Creative Commons Attribution Non-Commercial License (http://creativecommons.org/licenses/by$\mathrm{nc} / 3.0 /$ ), which permits unrestricted, non-commercial use, distribution and reproduction in any medium, provided the work is properly cited. 